\title{
La otra lista del Patrimonio Mundial. El cambio cultural
}

\author{
Ma Dolores Ruiz de Lacanal
}

Para la conservación de la memoria de Fernando, nuestro hijo

\begin{abstract}
Resumen: Se trata de un artículo de opinión sobre aspectos teóricos de la Conservación del Patrimonio Cultural, concretamente sobre conceptos y términos. El artículo parte de un concepto bien conocido como es la Lista del Patrimonio Mundial realizada por la UNESCO con el fin de proteger aquellos lugares que tienen un valor universal excepcional, lugares con historia y/o dignos de ser conservados por su extraordinaria belleza. Tomando como referencia esta lista, el artículo plantea y propone hacer otra o completarla de manera que comprenda los lugares del planeta donde existe un vacío cultural, lugares donde la cultura y la identidad cultural están siendo destruidas o lugares donde se manifiesta claramente la pérdida de valores humanos y culturales.
\end{abstract}

Se revisará el concepto de lugares de la memoria desarrollado por Pierre Nora y los lugares que se quieren olvidar de Pierre VidalNaquet. Se presentarán las ideas de Maurice Halbwachs y Marc Augé sobre los lugares de la memoria colectiva y los no-lugares y finalmente se recurrirá a los conceptos de humanidad, destrucción y barbarie abordados por notables filósofos y pensadores del siglo XX y XXI como el español José Ortega y Gasset y el francés Tzvetan Todorov. El artículo se realiza desde la conciencia de que el hombre y el patrimonio cultural se encuentran en peligro por distintas causas en diferentes partes del planeta. Se reconoce que los niveles de protección nacional e internacional no son suficientes y que junto a la lista de los lugares de interés cultural, podemos hacer otro mapa del mundo con los lugares que sufren los efectos del cambio cultural.

Palabras clave: lugares de la memoria, lugares de la memoria colectiva, no-lugar, derechos humanos, humanidad, deshumanización, inhumanidad, cambio cultural

\section{The other World Heritage list. Cultural change}

Abstract: It is an opinion article on theoretical aspects of the Conservation of Cultural Heritage, specifically on concepts and terms. The article starts from a well-known concept such as the World Heritage List, carried out by the UNESCO in order to protect those places that have exceptional universal value to reflect on the possibility of generating another list, the one that would show the places on the planet, where there is a cultural void or a cultural change, not only because of the absence or lack of manifestations of universal value, but this purpose clearly manifesting the loss of human and cultural values.

Concepts such as the places of the memory of Pierre Nora, or the places not remembered of Pierre Vidal-Naquet are reviewed. The ideas of Maurice Halbwachs and Marc Augé on the places of collective memory and non-places are presented. And notable philosophers and thinkers of the twentieth and twenty-first century such as the spanish José Ortega y Gasset, the french Tzetan Tdorov are present those ideas that help us understand, in the context of globalization, the places where culture and cultural identity are destroyed. The article starts from the awareness that the human and cultural heritage is increasingly threatened by different causes that can lead to its extermination and total disappearance, in some parts of the planet. It is also recognized that protection at the national and international levels is incomplete and that together with the places that arouse worldwide interest in its cultural heritage, we must place on the map of the world those that suffer the cultural change.

Keyword: places of memory, places of collective memory, non-place, human rights, humanity, dehumanization, inhumanity, cultural change

\section{A outra lista do Património Mundial. Mudança cultural}

Resumo:Trata-se de um artigo de opinião sobre aspetos teóricos da Conservação do Património Cultural, especificamente sobre conceitos e termos. O artigo parte de um conceito bem conhecido como é a Lista do Património Mundial realizada pela UNESCO com o propósito 
de proteger aqueles locais que têm um valor universal excecional, lugares com história e /ou dignos de serem preservados pela sua extraordinária beleza. Tomando esta lista como referência, o artigo propõe fazer outra ou completá-la para que se compreenda os lugares do planeta onde há um vazio cultural, os lugares onde a cultura e a identidade cultural estão sendo destruídas ou os lugares onde se manifesta claramente a perda de valores humanos e culturais.

Será feita uma revisão ao conceito de lugares da memória desenvolvido por Pierre Nora e os lugares que se querem esquecer por Pierre Vidal-Naquet. Serão apresentadas as ideias de Maurice Halbwachs e Marc Augé sobre os lugares da memória coletiva e os não-lugares e, por último, serão utilizados os conceitos de humanidade, destruição e barbárie abordados por notáveis filósofos e pensadores dos séculos XX e XXI como o espanhol José Ortega y Gasset e o francês Tzvetan Todorov. O artigo baseia-se na consciência de que o homem e o património cultural estão ameaçados por diferentes causas em diferentes partes do planeta. É reconhecido que os níveis de proteção nacional e internacional não são suficientes e que junto com a lista de locais de interesse cultural, podemos fazer um outro mapa do mundo com os locais que sofrem os efeitos da mudança cultural.

Palavras-chave: lugares de memória, lugares de memória coletiva, não-lugar, direitos humanos, humanidade, desumanização, desumanidade, mudança cultural

\section{Introducción}

La búsqueda de palabras que nos ayuden a identificar y localizar una realidad internacional actual compleja y en cierta medida silenciada no es fácil. Si partimos de un claro compromiso con los valores humanos implícitos bajo el concepto de cultura, deberíamos ampliar la protección de monumentos, bienes culturales o tradiciones y abarcar también aquellos lugares donde las manifestaciones culturales son destruidas y donde la protección del hombre, como verdadero soporte de la cultura, es necesaria.

El artículo busca un marco teórico y conceptual que ayude a identificar los lugares donde se produce la destrucción del ser humano, su propia identidad cultural y sus manifestaciones culturales. Esta cuestión es importante, hasta el punto que es un objetivo prioritario en los tiempos que corren, en los que es necesario determinar claramente el problema, trabajar con una clara y precisa terminología para pasar después a identificar, clasificar diferentes tipologías y plantear estrategias. Quizás sólo después de un estudio de este tipo podamos plantearnos para qué sirve la cultura, si no es para enfrentarnos a aquellas causas que generan la destrucción de la vida y la cultura, fundamentalmente como defensa de los derechos humanos frente al terror, al miedo, a la explotación y a la tortura.

La ausencia de cultura, la ausencia de patrimonio y la carencia de valores humanos atentan contra el propio ser humano, deshumanizándolo y despojándolo de la capacidad de crear e interpretar los significados culturales.

No solo es necesaria una reacción frente al cambio climático, también es necesario comprender qué es el cambio cultural en el planeta. Si por cambio climático entendemos que existe una causa detrás, como es el calentamiento global y tiene múltiples consecuencias negativas en los sistemas físicos, biológicos y humanos, entre otros efectos, por cambio cultural entendemos que también hay una causa detrás, una dinámica global, que tiene consecuencias negativas en los sistemas culturales y humanos.
La identificación y clasificación de casos como los campos de refugiados, lugares de frontera, lugares en conflicto armado, lugares de tortura y sin derechos humanos, es un trabajo complejo, pero necesario. Aunque son temas muy complejos y amplios y bien merecen la atención de muchos otros investigadores, el objetivo de este artículo no es otro que hacer una aproximación al tema.

\section{La Lista del Patrimonio Mundial de la UNESCO y la otra lista}

Mientras que existe una terminología bien conocida que comprende términos como patrimonio de la humanidad, bienes de interés cultural, museo o patrimonio cultural, no ocurre lo mismo cuando nos referimos a lugares que están ligados a la degradación del espíritu humano y a la devastación de las civilizaciones, a los que no les hemos puesto nombre.

¿Cómo podríamos llamar a esos lugares donde la Humanidad es destruida? Lugares sin derechos humanos. ¿Cómo podríamos hacer un listado de lugares donde el Patrimonio Mundial de la Humanidad brilla por su ausencia, cómo se podría identificar el vacío cultural y quién podría llevarla a cabo?

Recordemos que ha sido la UNESCO ${ }^{[1]}$, como organismo dedicado a la educación y la cultura, la institución que ha desarrollado numerosas listas con el fin de proteger a la humanidad de la pérdida de valores excepcionales. Entre estas figuran la Lista de los Lugares del Patrimonio de la Humanidad (World Heritage) ${ }^{[2]}$, la Lista del Patrimonio Cultural Intangible (Intangible Cultural Heritage), la Lista de las Ciudades Creativas (Creative City), el Registro de la Memoria del Mundo ( Memory of the World Register), el Listado de las Reservas de la Biosfera (Biosfhere Reserves), la Lista de los Geoparques (Unesco Global Geopark) o el Atlas de las Lenguas del Mundo en Peligro (UNESCO Atlas of World's Languages in Danger).

Pero no existe una lista de los lugares del mundo donde la propia Humanidad y por tanto la cultura está o fue 
puesta en peligro. Se nos viene a la cabeza lugares que en el pasado sufrieron conflictos armados como Hiroshima, Nagasaki o Guernica. Y también lugares del pasado reciente o del presente: Bosnia, Sierra Leona, los armenios en Turquía, los tutsis en Ruanda o El Salvador.

Se trata de crear una herramienta capaz de recordar al ser humano, la propia fragilidad de la Humanidad, su condición vulnerable, no solo frente a acontecimientos provocados por la naturaleza, sino también por el hombre. Resultaría relevante y educativo si en la Lista del Patrimonio mundial se añadieran aquellos lugares que conservan valores excepcionales para la memoria del ser humano, que recuerdan la importancia de la protección del humano, a la par que se protege el patrimonio natural y cultural excepcional. En el año 1979 la UNESCO dio un gran paso en este sentido al declarar Patrimonio de la Humanidad uno de estos lugares, al introducir un lugar de crímenes de guerra alemanes en la Polonia ocupada, formado por dos campos de concentración, Auschwitz I y Auschwitz-Birkenau, pero se hizo de manera excepcional pudiéndose ampliar la lista.

En el marco teórico, si bien a lo largo del siglo $X X$ se han realizado muchas cartas y recomendaciones para proteger el patrimonio natural y cultural, no existe ningún documento, donde de manera explícita se defienda al hombre como soporte de la cultura, en relación a poblaciones en tránsito, a la esclavitud y la explotación humana, conflictos armados, zonas de paso o muros, espacios de la vergüenza o migrantes, es decir, donde se defienda la protección de la cultura y se denuncie la destrucción de los sistemas culturales del mundo. No encontramos documentos donde de manera expresa se señale la intrínseca relación entre el hombre y la cultura. Durante el siglo XX, la Carta de Atenas (1931) marcó el sentido de la protección referida a aquellas "obras maestras en las cuales la civilización ha encontrado su más alta expresión y que aparecen amenazadas" separando el concepto de conservación en varias direcciones, por un lado la conservación de obras maestras, por otra la conservación del medio natural o medio ambiente y por otra y desligado de ambos, la conservación humanitaria, que atiende a los seres humanos no como soportes de cultura, quedando desligada la destrucción de los seres humanos ${ }^{[3]}$ de la destrucción de la cultura y esta entendida en relación a objetos, monumentos, yacimientos o lugares de valor excepcional.

En el siglo XXI se siente la necesidad de volver a reconsiderar las relaciones entre la cultura y los seres humanos. Hasta el punto de que proponemos buscar los lugares donde el ser humano y sus valores culturales se sienten amenazados para construir una lista que detecte los vacíos de una realidad patrimonial en un ámbito internacional y global. Precisamente ahora cuando empezamos a entender la conservación del medio ambiente del planeta como un problema global es cuando empezamos a entender que la conservación del ser humano y la cultura deben ser entendidas bajo la idea de la globalización y el cambio cultural.

Hay zonas del planeta donde la ausencia de valores de conciencia, humanos y espirituales en una persona o en una sociedad, tiene como resultado una sociedad cruel e inhumana, dejando sentir un vacío cultural. El vacío cultural sería aquel que deja la ausencia o la destrucción de la cultura, aquel que genera la destrucción del ser humano y que indudablemente afecta a la Humanidad, poniéndola en peligro.

Esta otra lista, debería ser, igual que la Lista del Patrimonio Mundial, resultado de un frente mundial común y enumeraría los lugares donde la destrucción del patrimonio cultural y humano es una realidad, lugares donde el vacío cultural se manifiesta o incide en la degradación y pérdida de la naturaleza y la condición humana, en la desnaturalización y deshumanización [4], provocando la muerte del ser humano y su desidentificación.

El vacío cultural está en estrecha relación con la destrucción de los valores humanos y debe ser entendido como la no conservación y destrucción del ser humano. Identificar los lugares del planeta donde existen cámaras o espacios donde el ser humano no tiene salida porque se "carece de valores universales y la humanidad está ausente", obliga a catalogarlos como un lugar no turístico, lugar "no visitable" por no aportar al ser humano ni educación ni deleite. Serían registrados, divulgados y conocidos por la propia humanidad, convirtiéndose su difusión en un elemento revelador sobre los factores producidos por el cambio cultural. La otra lista contemplaría lugares donde los atentados contra el ser humano deben ser considerados además de inhumanos, atentados a la cultura, porque allí donde haya un ser humano hay un verdadero soporte de la cultura y una gran maravilla, cuya destrucción es en sí misma una barbarie y un perjuicio para toda la humanidad. [Figura 3].

Estos lugares deben ser nombrados, identificados, catalogados, además de difundidos como lugares afectados por un cambio cultural. Principalmente aquellos donde el ser humano está en peligro y es sometido a sufrimientos, donde su identidad cultural y la naturaleza humana son destruidas o exterminadas.

Si la Lista del Patrimonio Mundial identifica lugares que sobresalen por su belleza, por su historia y por portar valores significativos para la humanidad, los lugares inhumanos serán aquellos que muestran la muerte, el dolor humano y las carencias vitales y culturales. No serán bellos, incluso hay quién los ha llamado lugares traumáticos, referidos a las cámaras de exterminio del pasado (Galán 2018), pero lo que está claro es que es urgente identificar los que existen actualmente, aquellos que están bajo los efectos del cambio cultural por el bien de la supervivencia de la propia Humanidad. 


\section{Buscando los conceptos y la terminología}

\section{-Sobre los lugares de la memoria de Pierre Nora}

Para los objetivos de este trabajo, la creación de una lista diferente o complementaria a la Lista del Patrimonio Mundial, puede ayudar el concepto desarrollado por el historiador francés Pierre Nora: lugares de la memoria. Acuñado en los ochenta, vino a señalar la importancia de relacionar la cultura no con monumentos u objetos materiales o físicos, sino con realidades inmateriales, abstractas y simbólicas ligadas con fuerza a los seres humanos vivos y contemporáneos ${ }^{[5]}$.

Nos interesa como a Nora el presente y lo que vivimos, en relación al planeta y a nuestro entorno y encontramos en este autor el nexo de unión entre los lugares y el ser humano, a través de esa materia o pegamento que une y liga el espacio y los acontecimientos con nuestra propia vida y nuestros recuerdos, la memoria. Los lugares de la memoria son lugares ligados a la memoria de personas que viven actualmente, que tienen la capacidad de interpretarlos y conservar sus significados (Nora 1984).

Este término nos ayuda a comprender que la otra lista contenga fundamentalmente lugares que nos afectan, lugares que interpretamos, lugares que registramos porque somos o fuimos testigos de un evento o acontecimiento que nos dotó de conciencia. Los lugares de la memoria mundial serían, siguiendo a P. Nora, lugares ligados a la realidad contemporánea (ligados a la memoria y no a la historia), conservados por nuestra conciencia actual individual o colectiva, de los cuales seríamos nosotros sus testigos, sus intérpretes.

Esta metodología, la de Pierre Nora, nos ayuda a comprender que los lugares se unen al ser humano a través de su propia memoria, que le dota de imágenes, recuerdos, sensaciones y emociones.

Cualquier lugar del planeta, puede estar en el registro mental humano, puede ser ese lugar de la memoria, en cuyo espacio se generó un testimonio cultural del que fuimos testigos, lo que nos permitirá actuar con la legitimidad que da el comprenderlos, interpretarlos y por tanto también musealizarlos, explicarlos o protegerlos.

Mucho se ha escrito sobre este concepto ${ }^{[6]}$ sin embargo, a los efectos de este estudio, nos interesa resaltar que siguiendo a Pierre Nora, probablemente parte de esos lugares de la nueva lista serán lugares de la memoria de la humanidad.

Concretamos finalmente algunos lugares mantenidos vivos en la memoria, como por ejemplo, los campos de concentración de Auschwitz I y Auschwitz-Birkenau, declarados en el año 1979 por la Unesco Patrimonio de la Humanidad. A estos lugares de crímenes de guerra podrían sumarse bien en la misma lista o en la otra: Mauthasen, Dachau, Sachsenhausen, Ravensbrück. Buchenwald, entre otros. Pero también otros campos actuales y contemporáneos. [figuras 1 y 2].



Figura 1.- La entrada a Auschwitz. http://historia.nationalgeographic.com.es/a/27-enero-dia-internacional-conmemoracion-victimas-holocausto 12309/6 [consulta: 15/09/2020].

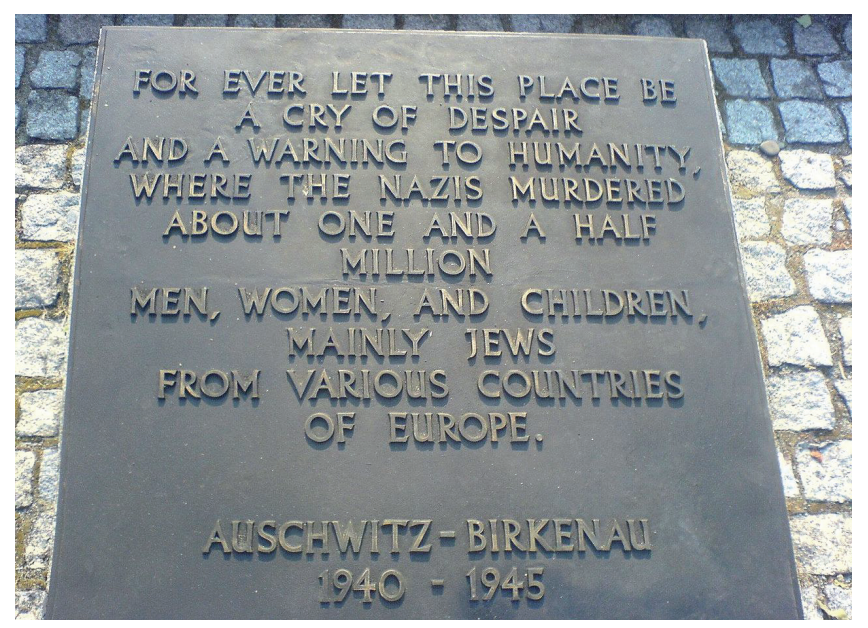

Figura 2.- Placa conmemorativa en la entrada de Auschwitz. http://historia.nationalgeographic.com.es/a/27-enero-diainternacional-conmemoracion-victimas-holocausto 12309/6 [consulta: 15/09/2020].

- Sobre los lugares que se quieren olvidar de Pierre_VidalNaquet

El segundo autor que nos ayuda a precisar el argumento de este artículo, a dar un nombre a estos lugares que pueden formar parte de esa otra lista o completar la lista realizada por la Unesco es Pierre Vidal-Naquet ${ }^{[7]}$.

Pierre Vidal-Naquet fue un historiador francés cuya investigación estuvo centrada en la antigua Grecia, que tomó una postura activista en contra de la guerra de Vietnam, las torturas y los horrores de la represión francesa en Argelia, las guerras de Irak e hizo frente contra el Revisionismo histórico (negacionismo) del holocausto nazi, al que dedicó varias de sus obras, entre ellas Les Assassins de la memoire, y Les juifs, la mémoire et le présent.

En estos escritos se muestra que los lugares donde se desarrollan los conflictos son silenciados, olvidados o no recordados intencionadamente. 
Si unimos los argumentos de P. Nora, con los argumentos de Pierre Vidal-Naquet, se puede aseverar que la lista tendrá no solo lugares de la memoria, sino también lugares olvidados, silenciados o intencionalmente ocultos.

En este sentido y siguiendo sus pasos, cabría preguntarnos por los lugares que se han olvidado o silenciado. Al señalar este autor que existen asesinos de la memoria, nos preguntamos: ¿Hay instituciones, naciones que intentan que no se conozca la memoria? Eso explicaría que hayan sido olvidados, no identificados y que hoy en la historia apenas se nombren las cámaras de exterminio, los campos de exterminio, los campos de la muerte o fábricas de la muerte, similares a los campos de concentración construidos durante la Segunda Guerra Mundial por el régimen nazi. Nos preguntamos, siguiendo a Vidal-Naquet (Vidal-Naquet 1994), si estamos, actualmente, en el siglo XXI, haciendo listas del Patrimonio Mundial, atendiendo a lugares de gran belleza y de gran interés histórico, artístico y monumental para la Humanidad, pero volviendo la espalda a los lugares donde se instala y se ha instalado la atrocidad.

Hemos recordado al historiador Pierre Vidal-Naquet, para identificar los lugares que luchan contra el olvido, no en vano su lucha contra la tortura y la desaparición de las personas a partir de la terrible experiencia en Auschwitz, le dotó de la fuerza del activismo.

El activismo nos lleva a otra pregunta: ¿Ayudará la identificación y el conocimiento a paliar la insensibilidad, la crueldad o la atrocidad?

La pregunta compartida por quienes nos siguen en la lectura de este artículo es si visibilizar estos lugares ayudará a liberar a la Humanidad de la crueldad, la insensibilidad y la atrocidad.

Efectivamente, lugares de la memoria como Villa Grimaldi en Santiago de Chile donde funcionó un emblemático centro de exterminio y tortura durante la dictadura de Pinochet, El Parque de la Memoria en Buenos Aires, ubicado en terrenos ganados al Río de La Plata que fuera la tumba anónima de muchos desaparecidos arrojados en los vuelos de la muerte, el Monumento a los Detenidos Desaparecidos en El Cerro de Montevideo en Uruguay y tantos otros, nos recuerdan que los lugares, los acontecimientos y las víctimas no caerán en el olvido, no serán recordadas según unos determinados marcos prefijados, y poco a poco, quedarán ligadas no a un marco geográfico y político prefijado, sino a toda la humanidad. [Figura 3]

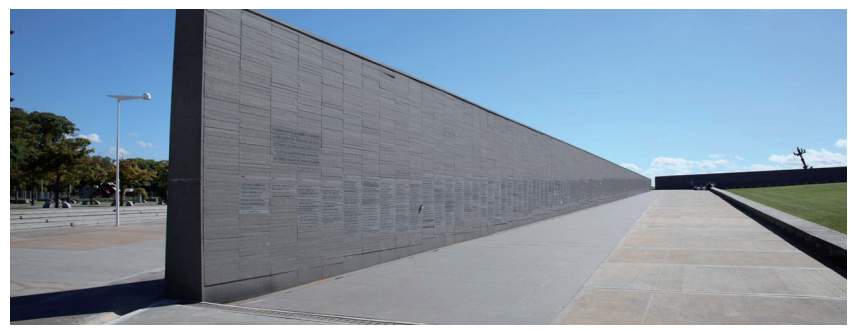

Figura 3.- Parque de la Memoria Buenos Aires. https://turismo. buenosaires.gob.ar/es/atractivo/parque-de-la-memoria [consulta: 15/09/2020].
- Los lugares de la memoria colectiva de Maurice Halbwachs y los no-lugares de Marc Augé

Para encontrar respuestas a la pregunta de cómo se produce la memoria colectiva hemos seguido buscando y hemos encontrado las reflexiones del psicólogo y sociólogo francés Maurice Halbwachs ${ }^{[8]}$, cuyas experiencias en el campo de concentración de Buchenwald, donde fue deportado, le llevaron al estudio del concepto de la memoria colectiva (Halbwachs 1950). Sus trabajos pioneros sobre la dimensión social de la memoria muestran la importancia de la trasmisión oral y el compartir comunitario (Halbwachs 2004: 9). Parece indicar que estos lugares que resisten al olvido, son preventivos y eficaces, cuando se configuran como memoria social y colectiva. Gracias a Maurice Halbwachs podemos comprender, en el marco de la globalización, cómo una memoria colectiva puede transformarse en memoria de la humanidad.

Eso indica que trabajar en una lista de los lugares de la memoria de la humanidad es importante, porque permite no solo compartir, difundir y hacer visible a los ojos de ésta, lugares de gran interés colectivo para generar la consciencia de la propia supervivencia, sino mover o activar hacia la comprensión del fenómeno del cambio cultural.

Es interesante también el concepto de no-lugar que aporta el antropológo Marc Augé [9] referido al espacio que carece de significados. Para Augé un lugar es un espacio dotado de identidad, relación e historia y un no -lugar es un espacio que carece de significados, es decir, que no tiene identidad ni relacional ni histórica (Augé 1993: 83).

Concretó Augé como no-lugares ciertos espacios anónimos urbanos, en aquel momento relacionados con unos determinados ámbitos creados en la posmodernidad, como lugares de transitoriedad: una autopista, una habitación de hotel, un aeropuerto o un supermercado. Decía de ellos que no personalizan, ni aportan a la identidad nada significativo, porque no son fáciles de interiorizar, ni su aspecto, ni sus componentes. Añadía, con respecto a estos no-lugares, que la relación de los humanos allí es más artificial, de manera que, si acaso, en ellos nos identificamos con un ticket de paso, un D.N.I, o una tarjeta de crédito ${ }^{[10]}$.

Tomando como referencia el concepto de Augé, buscamos un concepto que nos permita identificar los lugares en conflicto donde no hay ticket, ni D.N.I, ni tarjeta de crédito, sino narcotráfico y violencia, crímenes de estado, narco-cultura, industria del secuestro, homicidios y la deshumanización de la sociedad. Generados en el marco de la globalización, en relación a espacios de fronteras, alambradas y muros entre países, son lugares que sostienen los sistemas de deportación inhumanos, por ejemplo, la frontera entre Estados Unidos y México. Los espacios de frontera, incluidos los mares que engullen a personas, por ejemplo, en el Mediterráneo, son lugares de conflictos inhumanos. Dejamos que la artista Ana Teresa Fernández lo ilustre con su obra "Borrando la frontera."[11] [Figura 4]. 


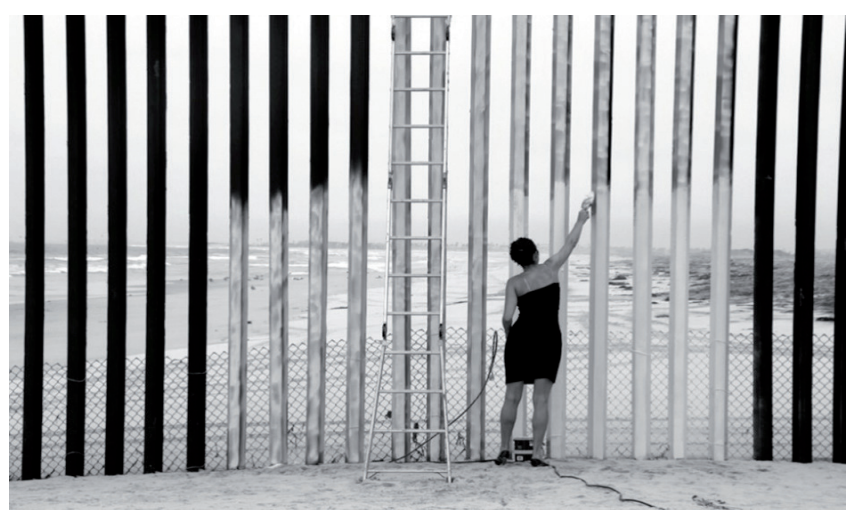

Figura 4.-"Borrando la frontera" de Ana Teresa Fernández. https:// www.codigonuevo.com/entretenimiento/artista-consiguioborrar-frontera-mexico-unidos [consulta: 8/08/2020]

- Sobre los lugares de la deshumanización de José Ortega y Gasset y de la barbarie de Tzvetan Todorov

Para buscar e identificar los lugares de la otra lista hay que rechazar la idea de que puedan ser lugares anodinos, más bien habría que decir, que son lugares de deshumanización, de barbarie y de destrucción. Si bien para Augé aquellos nolugares son elementos significativos de una forma de vida o una cultura posmoderna, para este estudio, los lugares de la otra lista son lugares que han existido siempre. Con George Steiner podríamos decir que "la inhumanidad es perenne".

Aceptamos sin embargo, que cada época tiene sus específicos comportamientos ligados a tecnologías, mentalidades, a cuestiones sociales y económicas específicas, de manera que existe una inhumanidad histórica. Es decir, aunque la inhumanidad es perenne, cada época perfila y concreta las maneras de inhumanidad o de vacío cultural que le definen.

Por tanto, la lista que haríamos sería contemporánea y en el marco de la globalización, para señalar los lugares ligados a la supervivencia, creados por los seres humanos para destruir al ser humano, deshumanizarlo y destruirlo.

Para avanzar, debemos volver al concepto de destrucción de la identidad cultural. Y podemos citar en este sentido a pensadores y filósofos que trataron este concepto, por ejemplo, el español José Ortega y Gasset ${ }^{[12]}$ y el francés Tzvetan Todorov ${ }^{[13]}$ que afrontaron el concepto de humanidad e inhumanidad.

Rechazamos la idea de identificar estos lugares con un grupo social, con una nación o con unos colectivos concretos y asumimos la idea de hombres sin memoria, que utilizó Ortega y Gasset (Ortega y Gasset 1929), o el término barbarie en la línea de Tvzetan Todorov al identificar lugares del planeta, donde los seres humanos están perdiendo sus derechos, son expoliados de su condición identitaria y cultural (Todorov 1995).

Mirar de frente a esos lugares, donde el ser humano ha sido despojado de su identidad personal y social y muere por deshumanización o por la barbarie es identificar los lugares de vacío cultural.

\section{- Sobre la memoria lúcida a partir de Roland Barthes}

Finalmente, para identificar los lugares de la otra lista, necesitamos contar con la lucidez. Un término, con el que despejó Roland Barthes ${ }^{[14]}$ ciertas preguntas sobre un campo tan ajeno al tema que tratamos, como es la fotografía. Para R. Barthes, la cámara lúcida recupera el sentido de la fotografía, al identificar a su madre en una imagen tras su fallecimiento. Entonces, señala Barthes, la imagen adquiere un gran e insustituible significado (Barthes 1980).

Queremos aplicar la lucidez, para encontrar los lugares de la otra lista y para ello nos será de gran utilidad anotar esta característica, señalando que los lugares sin humanidad se encuentran ligados a una vivencia o una memoria lúcida. En este caso, ambos, lugar y dolor, se muestran con claridad en un concepto hasta ahora desconocido, reflejo de la pérdida de un hijo, de un familiar desaparecido. La memoria en este caso es lúcida, es decir, actúa aplicando al lugar un significado y conserva con precisión y reiteración, sin que sea posible el natural olvido, de manera que el sufrimiento del ser humano infligido por otro ser humano, en un contexto social aprobado, admitido e incluso desarrollado por el estado, marca la memoria lúcida del afectado y después impregna el lugar aportando significados a la memoria colectiva, para hacerlo después a toda la Humanidad.

"Un lugar sin humanidad" es un lugar sin cultura donde actualmente un ser humano es deportado, desintegrado y deshumanizado. Un ser humano es deportado a su país, para que allí muera bajo el formato de suicidio y sea definitivamente exterminado. Un lugar sin humanidad, es aquel donde unos seres humanos desaparecen, sin que quede un registro o huellas de sus vidas.

En resumen, la memoria lúcida, es un concepto que nos permite relacionar un lugar con una herida o dolor por la pérdida de un ser humano, que ha sufrido la tortura y la degradación, la destrucción de su identidad cultural, sin que la herida pueda sanar, cicatrizar o curar nunca. Esta memoria lúcida no es otra cosa que la punzada del dolor que actúa cimbreando los cimientos directos primero, después de la colectividad y la nación, para afectar después a todos. No solo se pierde un hijo, un ser vivo y con él su futuro individual y familiar, sino que se produce la devastación de las raíces de la comunidad y por extensión se destruyen los fundamentos de una civilización que sostiene a esos individuos. Se hiere a una nación pero además es una afrenta a la humanidad.

En resumen, la otra lista contiene una relación de lugares o territorios de dolor, que suscita la inhumanidad, lugares de destrucción y deshumanización, marcados con precisión 
por la memoria lúcida. Por tanto, identificaremos los lugares que buscamos, gracias a la ayuda de los que han registrado el dolor imborrable de la pérdida de un ser humano de manera inhumana.

Pongamos un caso claro de lugar de memoria lúcida, por ejemplo, las Madres de Plaza de Mayo fundada en esta plaza en 1977 como lugar de la memoria de la desaparición de 30.000 jóvenes en Argentina ${ }^{[15]}$, o el Anti-monumento +43 por los jóvenes desaparecidos de la Normal Rural de Ayotzinapa colocado en el año 2015 en la Avenida Paseo de la Reforma de Acapulco (México) ${ }^{[16 .]}$ [Figuras 5 y 6]



Figura 5.- Madres Plaza de Mayo. https://clate.org/noticias/a43-anos-de-la-primera-ronda-de-madres-de-plaza-de-mayo/ [consulta: 15/09/2020].

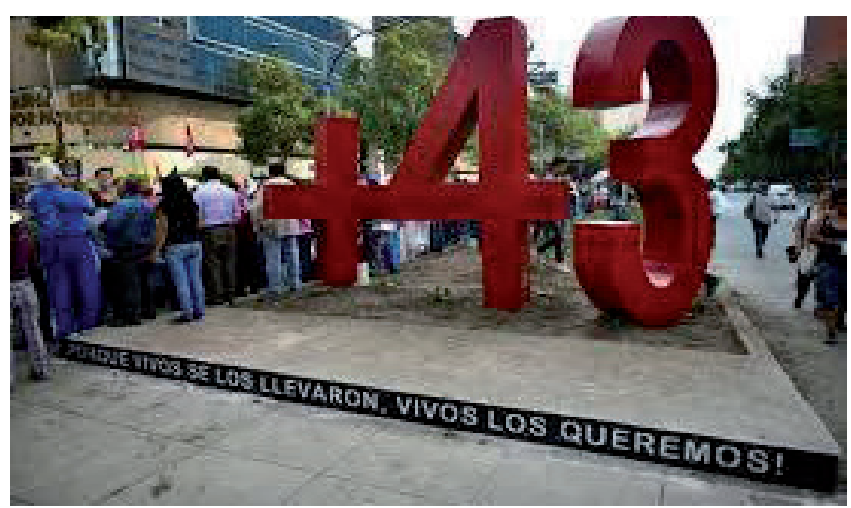

Figura 6.- Antimonumento +43 , México. https://es.wikipedia. org/wiki/Antimonumento [consulta: 8/08/2020].

\section{Los criterios para identificar los lugares de la otra lista}

Como resultado de la lectura de estos autores, sociólogos, psicólogos, filósofos y pensadores, llegamos a ver con bastante claridad algunos criterios que permiten identificar los lugares de la otra lista.

1. Atendiendo a la lectura de Pierre Nora, hemos encontrado en el concepto de lugares de la memoria un puente para pasar del concepto patrimonio mundial basado en valores históricos, artísticos o arqueológicos a una posible Lista del Patrimonio de la Inhumanidad, en relación a valores relacionados con la conciencia de la supervivencia del ser humano, en relación a la imprescindible memoria y la conservación de la civilización.
2. Siguiendo a Pierre_Vidal-Naquet, comprendemos que aunque hay lugares que son intencionadamente olvidados, resisten en la medida en que resiste la memoria. Hemos aprendido a buscar esos lugares-silencio o silenciados, lugares-olvido u olvidados (Camps 2010).

3. Siguiendo a Maurice Halbwachs podemos comprender mejor cómo los lugares de la memoria se convierten en lugares de interés de la memoria colectiva.

4. En relación a Marc Augé, hemos entendido que igual que el concepto de no-lugar identifica ciertos lugares de tránsito de la sociedad contemporánea, existen otros lugares donde el proceso de la despersonalización y la transitoriedad pueden llegar a desintegrar al ser humano y aniquilarlo.

5. A partir de estos conceptos se pueden presentar los lugares que favorecen la desintegración y la devastación de la identidad individual, siendo un caso claro los lugares de conflictos armados. Pero no sólo las guerras producen la inhumanización, también debemos tener en cuenta, junto a la muerte física de las personas, la muerte o pérdida de su identidad intangible e inmaterial. A veces no identificamos el conflicto y hay total impunidad. A veces, los mecanismos son complejos, bien porque existe un vacío cultural oficial y de manera oficial existe un sistema policial, un sistema judicial o un sistema sanitario, al servicio o en nombre de una seguridad nacional, encontrándonos finalmente con la destrucción y muerte, directa o indirecta de personas jóvenes y sensibles de la población.

6. Estos lugares son desfavorables al desarrollo humano, deshumanizadores y deshumanizantes.

7. Hemos percibido que el concepto de inhumanidad debe estar relacionado con estos lugares. En estos lugares el hombre, la gran maravilla del universo, pierde su valor. Allí, la verdadera obra de arte, la verdadera riqueza patrimonial y el tesoro fundamental, pierde su condición y naturaleza. En estos lugares a las personas se las identifican como "extranjero", "migrante" "refugiados" u otros, ni siquiera por un objeto (un ticket de paso, un D.N.I, la tarjeta de crédito). Allí el ser humano es agredido, destruido, desposeído de su identidad y deshumanizado.

8. Se ha realizado una breve aproximación al concepto de barbarie, siguiendo a Tzvetan Todorov para encontrar un adjetivo que señale los lugares de vacío cultural como lugares de la barbarie.

9. También hemos señalado, que la sensibilidad hacia estos lugares, viene en primer lugar por aquellos que guardan la memoria. Son lugares de la memoria lúcida, recordados e inolvidables para aquellos que sufrieron la pérdida.

10. Finalmente habría que señalar que son lugares que no están en la Historia Universal de la Civilización, en la 
Historia del Arte o en la Historia del Patrimonio Cultural. Son lugares olvidados por la Historia de la Conservación. Hemos repasado los manuales y publicaciones que se han escrito en los últimos años sobre la Historia de la Cultura y el Patrimonio cultural, para detectar que no se tienen presentes, por considerarse capítulos obscuros de la Historia de la Humanidad, no se citan o nombran estos lugares, espacios o territorios, entendiéndose que no hay nada notable que señalar. El propio vacío cultural hace que no se referencien, sin embargo, la destrucción del hombre y de la identidad cultural constituye un capítulo que está por escribir, sin duda uno de los más interesantes.

De igual manera que en los siglos pasados existieron las llamadas Cámaras de las Maravillas ricas en significados y con objetos de las ciencias naturales importantes y valiosos para los hombres de Ciencias, han existido a lo largo de la Historia y en el presente otras cámaras o lugares que fueron y son silenciadas o no referenciadas. El tránsito de las Cámaras de las Maravillas ${ }^{[16]}$ a las Cámaras de Exterminio es un camino actualmente insalvable. La Historia nos ha transmitido lugares interesantes creados para la conservación: archivos, gabinetes y cámaras de las maravillas, museos y bibliotecas, etc. Sin embargo, ha silenciado o no cita los lugares de destrucción. En esos lugares el ser humano, rodeado de un marco inhóspito y en peligro, conoció la tortura, un trato degradante e indigno, hasta perder su propia dignidad y humanidad. A la ausencia de cultura, al vacío cultural, no le hemos puesto nombre. [Figura 8]



Figura 7.- A la deriva con Ai Wei Wei. https://www.duendemad. com/es/n-164-el-libro-negro-del-mar/la-deriva-con-ai-wei-wei [consulta: 15/09/2020].

\section{Características de los Lugares de la otra lista}

I. Representan la capacidad destructiva de los hombres, al contrario que los lugares que forman parte de la Lista del Patrimonio Mundial, que representan el genio creativo o la capacidad creadora del hombre.

II. No testimonian el intercambio de valores humanos, en el pasado o en el presente, sino la destrucción de estos valores.

III. Aportan testimonios de destrucción de una tradición cultural o una civilización existente, bien porque está en vías de desaparición bien porque sufre los efectos del cambio cultural.
IV. Ofrecen ejemplos de destrucción, bien porque ilustran una etapa significativa de la historia humana bien porque marcan un registro de la memoria individual y colectiva o porque son síntomas que alertan sobre la necesidad de cambios vitales, estructurales y culturales. V. Son un ejemplo de inhumanidad, en cualquiera de sus manifestaciones.

VI. Están directamente asociados a eventos destructivos, donde las tradiciones vivas, las ideas o las creencias se ponen directamente en peligro.

\section{Conclusiones:}

Como conclusión podemos apreciar que son sitios específicos que responden a los siguientes criterios:

I. Son lugares de la memoria.

II. Son lugares de la memoria colectiva.

III. Son lugares no clasificados, no identificados, no difundidos (lugares silenciados).

IV. Son lugares que se intentan olvidar (lugares olvidados).

V. Son lugares de exterminio del ser humano y sus valores, entre ellos la propia memoria y la identidad cultural (algo más que un no-lugar)

VI. Son lugares de la deshumanización que favorecen, cuando no provocan, la desintegración y la devastación de la identidad individual y social (lugares de muerte, exterminio, tortura). Lugares de destrucción.

VII. Son lugares de la memoria lúcida (lugares de la memoria de los supervivientes)

Parece oportuno, seguir investigando en esta línea de investigación y profundizar en un tema muy complejo, que nos lleva a un nuevo planteamiento. Los conceptos y las ideas planteadas nos dejan abierta la puerta y nos invitan a poner más ejemplos. Indudablemente debemos ahora hacer la lista. Sin duda, una vez encontrados los criterios que marcarán nuestra búsqueda, podremos hallar más casos y clasificarlos en distintas tipologías. Podemos intentar describir sus características, aunque en principio no agotemos ni la clasificación, ni las tipologías, ni las características, pero eso será objetivo de otro artículo o publicación.

Sabiendo lo que buscamos, podemos ahora seguir nuestra investigación, para identificar y clasificar los lugares donde está ausente el Patrimonio Cultural o presente la inhumanidad. No es tarea fácil, ya que no encontramos antecedentes, no hay listados, ni registros.

\section{Notas}

[1] La UNESCO es la Organización de las Naciones Unidas para la Educación, la Ciencia y la Cultura. La UNESCO fue creada en 1945 y trata de establecer la paz mediante la cooperación internacional en materia de educación, ciencia y cultura. La Organización de las Naciones Unidas para la Educación, la Ciencia y la Cultura (en inglés United Nations Educational, Scientific and Cultural Organization), 
abreviado internacionalmente como Unesco, organiza en el año 1972 la Convención sobre la Protección del Patrimonio Mundial, Cultural y Natural con el objetivo de promover la identificación, la protección y la preservación del patrimonio mundial, cultural y natural considerado especialmente valioso para la humanidad. La Convención nace de la conciencia que le patrimonio está cada vez más amenazado por causas distintas que puede llevar a su total desaparición. También se admite que la protección a escala nacional es incompleta, teniendo en cuenta la magnitud de recursos que requiere.

[2] La primera de estas listas contemplan los lugares culturales "ligados a los testimonios del pasado y, más en general, a las de todas las civilizaciones". Patrimonio de la Humanidad o Patrimonio Mundial es el título conferido por la UNESCO a sitios específicos del planeta (sean bosque, montaña, lago, cueva, desierto, edificación, complejo arquitectónico, ruta cultural, paisaje cultural o ciudad) que han sido propuestos y confirmados para su inclusión en la lista mantenida por el programa Patrimonio de la Humanidad.

[3] Linares, Enrique, El triunfo de la muerte y otras matanzas masivas en el siglo XX. En línea. https://www.yumpu.com/en/ document/read/53242503/el-triunfo-de-la-muerte-genocidios-yotras-matanzas-masivas-en-el-siglo-xx. [consulta: 5/04/2020].

[4] Las referencias a los términos deshumanización, incultura, barbarie, y al contrario, civilización, ser humano, humanización, humanidad, son múltiples, por lo que citaremos sólo algunos, en concreto los estudios de José Ortega y Gasset sobre la deshumanización y de Tzvetan Todorov sobre la barbarie. En particular queremos citar el significado del término "barbarie" abordado por Todorov en el Miedo a los bárbaros y recordado entre otros por José Antonio Marina en Las culturas fracasadas. El talento y la estupidez de las sociedades, p.170-171.

[5] Pierre Nora: https://es.wikipedia.org/wiki/Pierre Nora. [consulta: 4/03/2020]. Nora, Pierre (1989). “Entre historia y memoria. La problemática de los lugares". (Edición 2009).

[6] Forcadell Álvarez, Carlos, 2005, “La historia social, de la clase a la identidad", en Hernández Sandoica, Helena (2005) Sobre la Historia actual. Entre política y cultura. Abada Editores, Madrid, pág. 33. “La historiografía española está aplicando ahora los presupuestos y recetas de los Lugares de la memoria de Pierre Nora, se están estudiando las estatuas, monumentos, callejeros, pero los lugares de la memoria de Nora eran unos lugares de la memoria nacionales, franceses y nacionalistas, y no se debe olvidar que algunos, en el vecino país, han criticado la propuesta de Nora como un artificio para sustituir la identidad de clases por la identidad nacional y se ha referido a la patología nacionalista de Nora".

[7] Pierre_Vidal-Naquet: https://es.wikipedia.org/wiki/Pierre Vidal-Naquet [consulta: 4/03/2020].

[8] Maurice Halbwachs: https://es.wikipedia.org/wiki/Maurice Halbwachs [consulta: 4/03/2020].

[9] Marc Augé: https://es.wikipedia.org/wiki/Marc Aug\%C3\%A9 [consulta: 4/03/2020].
[10] Augé, Marc (1993). Los "no lugares". Espacios del anonimato. Una antropología de la super modernidad. Barcelona. El libro de Marc Augé Non-lieux se publicó por primera vez en 1992.

[11] Sobre los artistas y la función social del arte, puede consultarse: Carvajal García, Aída: Realidad social en el arte mexicano del siglo XXI: migración, violencia de estado y exclusión/ inclusión de los pueblos indígenas en https://dialnet.unirioja.es/ servlet/articulo?codigo $=7218417$ [consulta: 8/08/2020].

[12] José Ortega y Gasset: https://es.wikipedia.org/wiki/ Jos\%C3\%A9 Ortega y Gasset [consulta: 4/03/2020].

[13] Tzvetan_Todorov: https://es.wikipedia.org/wiki/Tzvetan Todorov [consulta: 4/03/2020].

[14] BARTHES, ROLAND (1980) "La Chambre Claire" (2009). La Cámara Lúcida. Lo obvio y lo obtuso, Paidós Ibérico, Madrid. También: Roland Barthes: https://es.wikipedia.org/wiki/ Roland Barthes [consulta: 4/03/2020].

[15] (1996) Historia de las Madres de Plaza de Mayo, Ediciones Madres de Plaza de Mayo, Buenos Aires, Argentina.

[16] Término que designa un tipo de coleccionismo también llamados gabinetes de curiosidades, fueron espacios en los que los nobles y burgueses europeos de los siglos XVI, XVII y XVIII coleccionaban y exponían objetos exóticos provenientes de todos los rincones del mundo conocido. El término Cámara, o Kammer viene a significar estancia. Distinto significado y connotaciones tiene el término maravillas, muy usado a lo largo de la Historia de los Museos y el Patrimonio, que ha servido también para nombrar las Maravillas del mundo. Recordemos a Julius Von Schlosser (1908), Die Kunst- und Wunderkammern der Spätrenaissance.

\section{Referencias}

AUGÉ, M. (1993) Los "no lugares". Espacios del anonimato. Una antropología de la super modernidad. Barcelona.

BARTHES, R. (1980) "La Chambre Claire" (2009). La Cámara Lúcida. Lo obvio y lo obtuso, Paidós Ibérico, Madrid.

CAMPS, S. (2010) Voces silenciadas, Tres Culturas.

FORCADELL ÁLVAREZ, C. (2005). “La historia social, de la clase a la identidad", en Hernández Sandoica, Helena (2005). Sobre la Historia actual. Entre política y cultura. Abada Editores, Madrid.

GIL POISA, M. (2013) “Los no-lugares de la memoria: Barcelona 1888-1929" [en línea]. En: Ángulo Recto. Revista de estudios sobre la ciudad como espacio plural, vol. 5, núm. 2, pp. 81-93. En: http://www.ucm.es/info/angulo/volumen/Volumen05-2/ articulos06.htm. [ consulta: 5/04/2020].

GALÁN PÉREZ, A. (2018) "Conocer, conservar y comunicar el patrimonio de hechos traumáticos: el caso de la exposición 
'Auschwitz. No hace mucho. No muy lejos'"' en VI Congreso del GEIIC: (Grupo Español del International Institute of Conservation: ¿Y después? Control y mantenimiento del Patrimonio Cultural, una opción sostenible / coord. por International Institute for Conservation of Historic and Artistic Works, 2018, pp. 204-213 http://www.congreso2018.ge-iic. com/es/programa-preliminar/actas/.

GLOVER, J. (2007). Humanidad e inhumanidad, Cátedra, Madrid.

HALBWACHS, M. (2004a) Los marcos sociales de la memoria. Anthropos Editorial: Madrid.

HALBWACHS, M.(2004b) La memoria colectiva. Prensas Universitarias de Zaragoza: Zaragoza.

LINARES, E. (-) El triunfo de la muerte y otras matanzas masivas en el siglo XX [en línea]. https://www.yumpu.com/en/document/ read/53242503/el-triunfo-de-la-muerte-genocidios-y-otrasmatanzas-masivas-en-el-siglo-xx. [ consulta: 5/04/2020].

MARINA, J. A. (2010). Las culturas fracasadas. El talento y la estupidez de las sociedades. Editorial Anagrama. Colecciones Argumentos

MAGALI MÉNDEZ DE CASTELLÓN G., CASTELLÓN OSEGUEDA, J.R. (2018). Haciendo memoria. Construir desde el olvido en EL Salvador 25 años después de La firma de Los Acuerdos de Paz, en Transiciones políticas contemporáneas: singularidades nacionales de un fenómeno global / coord. por Carmen González Martínez, 2018, págs. 163-186

NORA, P. (1984). “Entre memoria e historia. La problemáticas de los lugares", En Les Lieux de Mémoire (Montevideo: Ediciones Trilce, 2008), 20

ORTEGA Y GASSET, J. (1929) La Rebelión de las Masas, (edición de 2005), España Libros, S.L.U. ( Edición 2009).

RAMÍREZ, M. T. (2011) "Mundo perceptivo y mundo cultural. Merleau-Ponty y la filosofía de la cultura", en L. Álvarez Falcón (coord.), La sombra de lo visible. Merleau-Ponty 1961-2011 (siete lecciones), Eutelequia, Madrid.

TODOROV, T. (1995a) Los abusos de la memoria. Barcelona: Paidós Asterisco.

TODOROV, T. (2008b) El miedo a los bárbaros, ed. Galaxia Gutenberg, Círculo de Lectores.

VIDAL-NAQUET, P. (1994) Los asesinos de la memoria, México D.F.

\section{Autor/es}

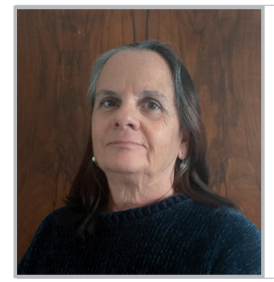

\section{Ma Dolores Ruiz de Lacanal}

mdrmus@us.es

Facultad de Bellas Artes Universidad de Sevilla.

Estudió Historia del Arte y Bellas Artes en la Universidad de Sevilla. Es profesora titular de la Facultad de Bellas Artes la Universidad de Sevilla, donde imparte en el Grado de Conservación y Restauración de Bienes Culturales, las asignaturas de Legislación del patrimonio e Historia de la Conservación y Restauración. Centra la docencia e investigación en la protección del patrimonio y dirige el Grupo de Investigación S.O.S. Patrimonio (HUM 673). A partir del año 2019, la profesora cambia el enfoque de sus investigaciones y centra su estudio de aquellos lugares donde se hace presente la destrucción del patrimonio humano y cultural. La muerte de su hijo con treinta años de edad el día 5 de abril de 2019, parará los relojes y conducirá su mirada hacia un territorio que no quiere señalar, mientras escucha en su memoria sus palabras: "es un lugar donde no se puede confiar en nadie, no hay lugares para habitar o para la convivencia ...."

Artículo enviado el 14/04/2020

Artículo aceptado el 05/09/2020

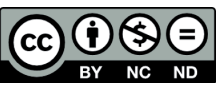

https://doi.org/10.37558/gec.v18i1.751 